'Fundação Oswaldo Cruz (Fiocruz), Escola Naciona de Saúde Pública Sergio Arouca (Ensp), Programa de Pós-Graduação em Saúde Pública - Rio de Janeiro (RJ), Brasil.

2 Fundação Oswaldo Cruz (Fiocruz), Escola Nacional de Saúde Pública Sergio Arouca (Ensp), Departamento de Direitos Humanos, Saúde e Diversidade Cultural - Rio de Janeiro (RJ), Brasil. aldopachecoferreira@gmail. com

\section{Tendência de malformações congênitas e utilização de agrotóxicos em commodities: um estudo ecológico}

\author{
Trend of congenital malformations and use of agrochemicals in \\ commodities: an ecological study
}

Lidiane Silva Dutra', Aldo Pacheco Ferreira ${ }^{2}$

DOI: 10.1590/0103-1104201912108

RESUMO O objetivo deste artigo foi analisar a tendência de malformações congênitas e a associação entre o uso de agrotóxicos em microrregiões de estados brasileiros que possuem maior produção de commodities agrícolas. Estudo ecológico de análise temporal conduzido com informações dos nascidos vivos (Sinasc/Ministério da Saúde), elaborando-se taxas de anomalias ocorridas entre 2000 e 2016. Foram encontradas taxas mais elevadas de anomalias congênitas nas microrregiões dos estados que apresentavam maiores produções de grãos. Essas anomalias podem ser advindas da exposição da população a agrotóxicos, sendo uma sinalização expressiva nos problemas de saúde pública.

PALAVRAS-CHAVE Agroquímicos. Anormalidades congênitas. Exposição ambiental.

ABSTRACT This article aims to analyze the trend of congenital malformations and the association with agrochemicals use in microregions of Brazilian states that have higher production of agricultural commodities. An ecological study of temporal analysis conducted with information on live births (Sinasc/Ministry of Health), elaborating rates of abnormalities occurring between 2000 and 2016. Higher rates of congenital abnormalities were found in the microregions of the states with the highest grain productions. These congenital abnormalities may be due to exposure of the population to agrochemicals, and a significant signaling in public health problems.

KEYWORDS Agrochemicals. Congenital abnormalities. Environmental exposure. 


\section{Introdução}

Os termos 'defeitos, malformações ou anomalias congênitas' são utilizados para descrever distúrbios do desenvolvimento presentes no nascimento, podendo ser estruturais, funcionais, metabólicos, comportamentais ou hereditários. As Malformações Congênitas (MC) são as principais causas de mortalidade fetal que representam um problema global, sendo que aproximadamente 8 milhões de crianças do mundo todo apresentam algum tipo de defeito congênito sério ${ }^{1}$. Apesar da maioria das MC não poder ser relacionada com uma causa específica, a exposição pré-natal a agrotóxicos é sugerida como um fator que aumenta o risco de teratogenicidade e suscetibilidade da maioria dos sistemas fetais durante certos períodos de desenvolvimento ${ }^{2}$.

Com relação aos defeitos congênitos, $40 \%$ a $45 \%$ das anomalias têm causas desconhecidas. A predisposição genética, como alterações cromossômicas e a mutação de genes, representam aproximadamente $28 \%$ das ocorrências; fatores ambientais representam aproximadamente 5 a 10\%, e a combinação entre influências genéticas e ambientais (herança multifatorial) representa $20 \%$ a $25 \%{ }^{3}$.

Os Disruptores Endócrinos (DE) agem, principalmente, interferindo nas funções dos hormônios naturais, pois possuem um forte potencial para se ligar aos receptores de estrogênio ou andrógenos ${ }^{4,5}$. Dessa forma, os DE podem ligar e ativar vários receptores hormonais e, em seguida, imitar a ação do hormônio natural (ação agonista), bem como podem se juntar a esses receptores sem ativá-los. Essa ação antagônica bloqueia os receptores e inibe sua ação. Finalmente, os DE também podem interferir na síntese, transporte, metabolismo e eliminação de hormônios, diminuindo a concentração de hormônios naturais ${ }^{6}$.

Os agrotóxicos são utilizados para a produção de culturas e em áreas urbanas para o controle de doenças transmitidas por vetores, sendo potencialmente tóxicos para outros organismos, incluindo seres humanos ${ }^{7}$. A exposição humana a agrotóxicos pode ocorrer ambientalmente, por meio do ar, do consumo via resíduos em alimentos e água, bem como ocupacionalmente, durante ou após a aplicação interna/externa ${ }^{8}$. $\mathrm{O}$ uso generalizado dos agrotóxicos, estimado em $2 \times 10^{9} \mathrm{~kg}$ em todo o mundo anualmente, levanta preocupações públicas significativas em relação à segurança desses produtos 9,10 .

Nesse contexto, a extensiva utilização de agrotóxicos, principalmente nos países em desenvolvimento, representa um dos fatores que podem influenciar no aumento de doenças relacionadas com a exposição ambiental. As economias desses países estão diretamente relacionadas com os produtos do agronegócio, e este modelo de desenvolvimento implica o uso crescente de aditivos químicos, o que justifica a preocupação acerca dos possíveis danos causados à saúde da população ao médio e longo prazo"1.

A mortalidade proporcional por MC no Brasil vem aumentando progressivamente. Em 2014, as mortes por MC representaram a segunda principal causa de mortalidade infantil e a principal causa de mortalidade pós-neonatal ${ }^{12}$. Existem ainda outros agravantes em relação aos agrotóxicos no contexto brasileiro: há insuficiência de dados sobre o consumo de agrotóxicos, os tipos e volumes utilizados nos municípios, a falta de conhecimento sobre o seu potencial tóxico, a carência de diagnósticos laboratoriais favorecendo o ocultamento e a invisibilidade desse importante problema de saúde pública ${ }^{13}$. Por conseguinte, o objetivo deste artigo é analisar a tendência de MC e a associação entre o uso de agrotóxicos em microrregiões de estados brasileiros que possuem maior produção de commodities agrícolas.

\section{Metodologia}

Trata-se de um estudo ecológico de análise temporal sobre a prevalência de MC.

Para a construção da variável de exposição, foram selecionados quatro grãos de cultivo, 
principais commodities agrícolas brasileiras que correspondem a maior parte da produção agrícola do País, sendo eles: algodão, cana-de-açúcar, milho e soja, que correspondem a mais de 70\% da área plantada do Brasil em 2016. Devido à ausência de dados sólidos sobre o uso de agrotóxicos no País, foram utilizados dados de área plantada de lavouras que foram obtidos na Produção Agrícola Municipal (PAM) do Sistema IBGE de Recuperação Automática do Instituto Brasileiro de Geografia e Estatística (IBGE-Sidra), entre os anos de 2000 e 2016, obtidos por intermédio do IBGE ${ }^{\mathbf{1 4}}$.

A partir desses dados, foram escolhidos alguns estados para serem analisados, cujas produções dessas commodities fossem as mais significativas no contexto nacional, sendo eles: Mato Grosso (MT), Paraná (PR), Rio Grande do Sul (RS) e São Paulo (SP). Os dados sobre área destinada ao plantio também foram utilizados para elaborar um ranking decrescente de produção para as microrregiões desses estados. Desse modo, as microrregiões de cada estado com maiores áreas destinadas às produções de commodities foram escolhidas para serem analisadas, variando entre três e seis microrregiões, de acordo com o tamanho delas. Sempre que possível, buscou-se considerar tanto a posição ocupada no ranking quanto a proximidade geográfica das microrregiões. Como mencionado anteriormente, não há dados sistematizados no País sobre o consumo de agrotóxicos. Assim, foi feita uma estimativa da exposição multiplicando-se a quantidade recomendada para aplicação do agrotóxico em cada tipo de cultura e a área destinada ao plantio de lavouras temporárias.

Foram escolhidos para serem quantificados agrotóxicos sabidamente reconhecidos como DE. A identificação dos agrotóxicos que apresentam essas propriedades foi baseada na pesquisa de Mnif et al..$^{15}$, resultando em um total de 27 agrotóxicos. Foram analisadas as bulas dos agrotóxicos com os ingredientes ativos selecionados. Como há grande variação nas quantidades indicadas para o uso dos agrotóxicos em cada tipo de plantio, foram verificadas, no mínimo, três e, no máximo, dez bulas para cada ingrediente ativo. Posteriormente, foi feita uma média com os valores encontrados. Além dos agrotóxicos, foram considerados na quantificação seus derivados e associações com outros compostos. As bulas foram obtidas por meio do sistema on-line Agrofit do Ministério da Agricultura, que permite a busca dos agrotóxicos por diversas maneiras (marca comercial, cultura, ingrediente ativo, classificação toxicológica e classificação ambiental). As consultas foram realizadas utilizando sempre o nome do ingrediente ativo ${ }^{16}$.

Também foram vistos dados sobre a comercialização de agrotóxicos nos estados entre 2000 e 2016. Os dados sobre a vendas de agrotóxicos foram obtidos por meio dos 'Relatórios de comercialização de agrotóxicos' disponibilizados pelo Instituto Brasileiro de Meio Ambiente e de Recursos Naturais Renováveis (Ibama) ${ }^{\mathbf{1 7}}$. Esses documentos apresentam somente os dados brutos sobre a comercialização nos estados, sem mencionar os ingredientes ativos comercializados. Também não existem dados sobre a comercialização nas microrregiões e municípios brasileiros, tampouco estão disponíveis dados sobre a utilização desses ingredientes ativos nas unidades da federação ou em suas microrregiões e municípios.

Após a escolha das microrregiões e a estimativa da exposição, foram calculadas taxas de MC (por mil nascimentos) para essas localidades e para o restante do estado no período de 2000 a 2016. A população do estudo foi constituída por nascidos vivos nos anos mencionados. As informações sobre os nascidos vivos foram obtidas do Sistema de Informação sobre Nascidos Vivos (Sinasc - Datasus) do Ministério da Saúde (Datasus, 2016). Esse é um sistema de informação de base populacional que agrega os registros contidos na declaração de nascidos vivos, o que permite diversas análises na área de saúde materno-infantil. Foram desconsiderados os casos de nascidos vivos com registro ignorado ou desconhecido.

Após a elaboração das taxas, foi feita a análise da tendência por intermédio da 
estimativa da variação percentual anual (Anual Percentage Change - APC) da taxa de prevalência de anomalias congênitas de 2000 a 2016 por meio de regressão de Poisson. Utilizouse o programa estatístico Joinpoint, versão 4.6.0.0 do Instituto Nacional do Câncer, EUA (Joinpoint, 2018). A técnica de joinpoint utiliza as taxas log-transformadas para identificar os pontos de inflexão (joinpoints), ao longo do período, capazes de descrever uma mudança significativa na tendência por meio da $\mathrm{APC}^{\mathbf{1 8}}$. Como os fenômenos biológicos nem sempre se comportam de maneira uniforme, uma taxa pode apresentar mudanças no ritmo de variação ao longo do tempo. Quando ocorre essa situação, a análise de segmentos pode representar melhor o fenômeno observado. Os testes de significância para escolha do melhor modelo basearam-se no método de permutação de Monte Carlo, considerando $\mathrm{p}<0,05$.

Além dessas análises, também foi calculado o Odds Ratio (OR) entre as microrregiões e o restante do estado para o período analisado.
O Intervalo de Confiança (IC) adotado para as análises foi de $95 \%$.

Este estudo foi aprovado pelo Comitê de Ética em pesquisa da Fundação Oswaldo Cruz, obedecendo à Resolução CNS n ${ }^{0}$ 196/9624, não implicando qualquer risco individual, uma vez que os dados coletados não apresentam informações pessoais.

\section{Resultados}

Nasceram vivas 25.812 .748 crianças nos estados analisados entre 2000 e 2016, das quais 156.275 apresentaram MC (0,61\%). A figura 1 apresenta a localização dos estados e microrregiões estudadas. Foram escolhidas para análises as seguintes microrregiões: Aripuanã, Arinos, Alto Teles Pires, Sinop e Rondonópolis (MT); Toledo, Cascavel e Guarapuava (PR); Santo Ângelo, Cruz Alta, Santiago e Campanha Ocidental (RS) e São José do Rio Preto, São Joaquim da Barra, Jaboticabal, Ribeirão Preto, Araraquara e Assis (SP).

Figura 1. Taxas de anomalias congênitas (por 1000 nascidos vivos) nos estados de Goiás/Distrito Federal, Mato Grosso, Paraná, Rio Grande do Sul e São Paulo, e nas microrregiões analisadas, 2000 a 2016

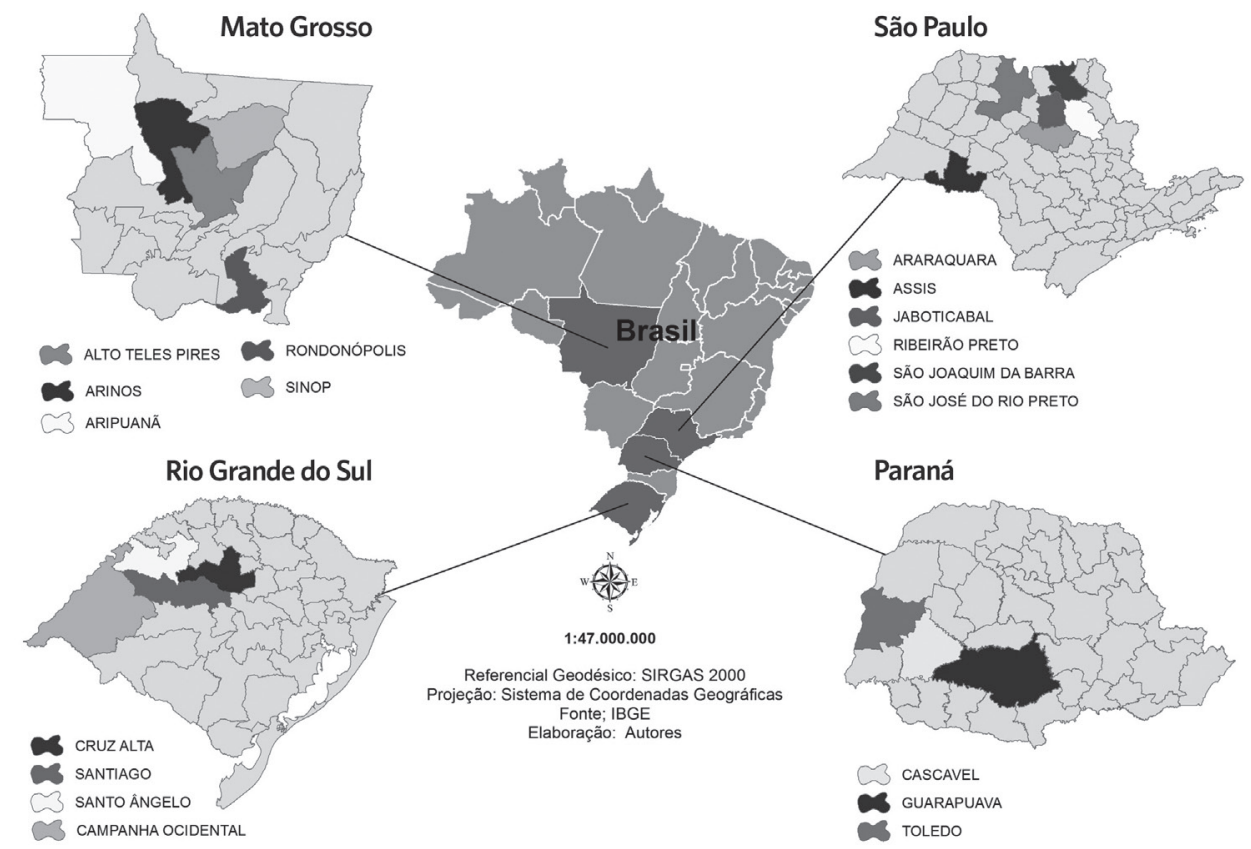

Fonte: Elaboração própria. 
A tabela 1 apresenta o número total de nascimentos e o número de $\mathrm{MC}$ nas microrregiões analisadas e nos estados entre 2000 e 2016. Também é apresentado o somatório da estimativa de consumo de agrotóxicos $\mathrm{DE}$ para estes anos. As taxas de MC nas microrregiões e estados variaram de $0,50 \%$ a $0,94 \%$, sendo sempre maiores nas microrregiões que, proporcionalmente, apresentam maiores estimativas de exposição aos agrotóxicos DE. Os riscos de $\mathrm{MC}$ apresentados para as microrregiões dos estados no período de 2000 a 2016 foram de 1,26; 1,30; 1,20 e 1,70, respectivamente, para os estados de MT, PR, RS e SP, sendo todos estatisticamente significativos.

Tabela 1. Odds Ratio e intervalos de confiança para nascidos vivos com malformações congênitas nos estados e nas microrregiões, e estimativa do consumo de agrotóxicos disruptores endócrinos, 2000 a 2016

\begin{tabular}{lrrrrrr}
\hline $\begin{array}{l}\text { Estados e } \\
\text { Microrregiões }\end{array}$ & Com MC & Sem MC & Odds Ratio & IC(95\%) & \% de MC & $\begin{array}{r}\text { Estimativa do consumo de } \\
\text { agrotóxicos } \mathbf{D E}^{\star}\end{array}$ \\
\hline MT' & 1.539 & 245.581 & 1,26 & $1,18-1,34$ & 0,63 & $1,2 \mathrm{E}+08$ \\
MT & 2.966 & 595.341 & & & 0,50 & $2,5 \mathrm{E}+08$ \\
PR' & 2.637 & 314.326 & 1,30 & $1,24-1,35$ & 0,84 & $4,9 E+07$ \\
PR & 15.313 & 2.366 .754 & & & 0,65 & $2,6 \mathrm{E}+08$ \\
RS' & 1.571 & 196.526 & 1,20 & $1,14-1,27$ & 0,80 & $4,3 E+07$ \\
RS & 18.659 & 2.807 .697 & & & 0,66 & $1,5 \mathrm{E}+08$ \\
SP' & 6.669 & 708.609 & 1,70 & $1,65-1,74$ & 0,94 & $8,7 \mathrm{E}+07$ \\
SP & 60.838 & 10.961 .160 & & & 0,56 & $2,9 E+08$ \\
\hline Total & $\mathbf{1 5 6 . 2 7 5}$ & $\mathbf{2 5 . 8 1 2 . 7 4 8}$ & & & $\mathbf{0 , 6 1}$ & $\mathbf{1 , 5 E + 0 9}$ \\
\hline
\end{tabular}

Fonte: Elaboração própria.

MC - Malformações congênitas; IC - Intervalo de confiança; DE - Disruptor endócrino.

(') microrregiões analisadas nos estados. ${ }^{\star}$ Quilolitros de agrotóxicos por hectare.

Na tabela 2, são apresentadas as taxas de incidência de $\mathrm{MC}$ ao nascer, que variaram entre 2,3 e 8,61 e entre 4,2 e 10,68, respectivamente, em 2000 e 2016, sendo sempre maiores nas microrregiões dos estados. O estado do PR e sua microrregião apresentaram tendências crescentes de MC para os anos de 2000 a 2012 e de 2000 a 2011, sendo ambos estatisticamente significativos com variações percentuais anuais (APC) de: $\mathrm{APC}=2,5^{*}(\mathrm{IC} 95 \%=1,6 ; 3,3)$ e APC $=2,8 *($ IC95\% $=1,3 ; 4,3)$ respectivamente. No período subsequente, de 2012 a 2016 e de 2011 a 2016, respectivamente, para o estado e para a microrregião, apenas o primeiro apresentou tendência de queda de AC estatisticamente significativa com variações percentuais anuais de: $\mathrm{APC}=-4,4 *(\mathrm{IC} 95 \%=-8,4 ;-0,1)$ e $\mathrm{APC}=-2,7$ (IC95\%=-7,0; 1,9).

As microrregiões dos estados de MT, RS e SP apresentaram tendências de crescimento de $\mathrm{AC}$ e variações percentuais anuais de: $\mathrm{APC}=2,1^{*}$ $(\mathrm{IC} 95 \%=0,6 ; 3,5) ; \mathrm{APC}=1,9 *(\mathrm{IC} 95 \%=0,1 ; 3,6)$ e $\mathrm{APC}=1,7 *(\mathrm{IC} 95 \%=0,9 ; 2,5)$ respectivamente. Por outro lado, os estados apresentaram tendência de queda de $\mathrm{MC}$ e variações percentuais anuais de: $\mathrm{APC}=-1,3 *$ (IC95\%=-2,0; $-0,5) ; \mathrm{APC}=0,1(\mathrm{IC} 95 \%=-0,3 ; 0,0)$ e $\mathrm{APC}=-0,2 *$ (IC95\%=-0,3; -0,1) respectivamente. Apenas o estado do RS não apresentou valores de queda estatisticamente significativos. 
Tabela 2. Taxas e análise de regressão joinpoint da tendência de malformações congênitas nos estados e nas microrregiões analisadas, 2000 a 2016

\begin{tabular}{|c|c|c|c|c|c|c|}
\hline \multirow[t]{2}{*}{ Região } & \multicolumn{2}{|c|}{$\begin{array}{r}\text { Taxa de Malformações Congênitas } \\
\text { (1000 nascidos vivos) }\end{array}$} & \multirow[t]{2}{*}{ Período } & \multirow[t]{2}{*}{$\begin{array}{r}\text { Variação Percentual } \\
\text { Anual (APC) }\end{array}$} & \multirow[t]{2}{*}{$\begin{array}{r}\text { Intervalo de } \\
\text { Confiança (IC) }\end{array}$} & \multirow[t]{2}{*}{ p-valor } \\
\hline & 2000 & 2016 & & & & \\
\hline$M T^{\prime}$ & 6,44 & 7,71 & $2000-2016$ & $2.1^{*}$ & $0.6 ; 3.5$ & 0.0 \\
\hline MT & 4,98 & 4,20 & $2000-2016$ & $-1.3^{\star}$ & $-2.0 ;-0.5$ & 0.0 \\
\hline \multirow[t]{2}{*}{$\mathrm{PR}^{\prime}$} & 7,07 & 8,65 & 2000 - 2011 & $2.8^{\star}$ & $1.3 ; 4.3$ & 0.0 \\
\hline & & & 2011 - 2016 & -2.7 & $-7.0 ; 1.9$ & 0.2 \\
\hline \multirow[t]{2}{*}{ PR } & 5,45 & 6,19 & $2000-2012$ & $2.5^{\star}$ & $1.6 ; 3.3$ & 0.0 \\
\hline & & & 2012 - 2016 & $-4.4^{\star}$ & $-8.4 ;-0.1$ & 0.0 \\
\hline $\mathrm{RS}^{\prime}$ & 7,24 & 7,45 & $2000-2016$ & $1.9^{*}$ & $0.1 ; 3.6$ & 0.0 \\
\hline RS & 6,69 & 6,69 & $2000-2016$ & -0.1 & $-0.3 ; 0.0$ & 0.1 \\
\hline$S P^{\prime}$ & 8,61 & 10,68 & $2000-2016$ & $1.7^{\star}$ & $0.9 ; 2.5$ & 0.0 \\
\hline SP & 5,59 & 5,48 & $2000-2016$ & $-0.2^{\star}$ & $-0.3 ;-0.1$ & 0.0 \\
\hline
\end{tabular}

Fonte: Elaboração própria.

(') microrregiões analisadas no estado. * Estatisticamente significativo.

A figura 2 apresenta dados referentes às taxas de incidência de MC ao nascer que variaram entre 2,3 e 8,61 e entre 4,2 e 10,68, respectivamente, entre 2000 e 2016 . O estado do PR e sua microrregião apresentaram dois períodos distintos de comportamento da taxa, enquanto os estados de MT, RS, SP e suas microrregiões apresentaram um único período.

Figura 2. Taxas de malformações congênitas (por 1000 nascidos vivos) nos estados de Mato Grosso, Paraná, Rio Grande do Sul e São Paulo e nas microrregiões analisadas, 2000 a 2016
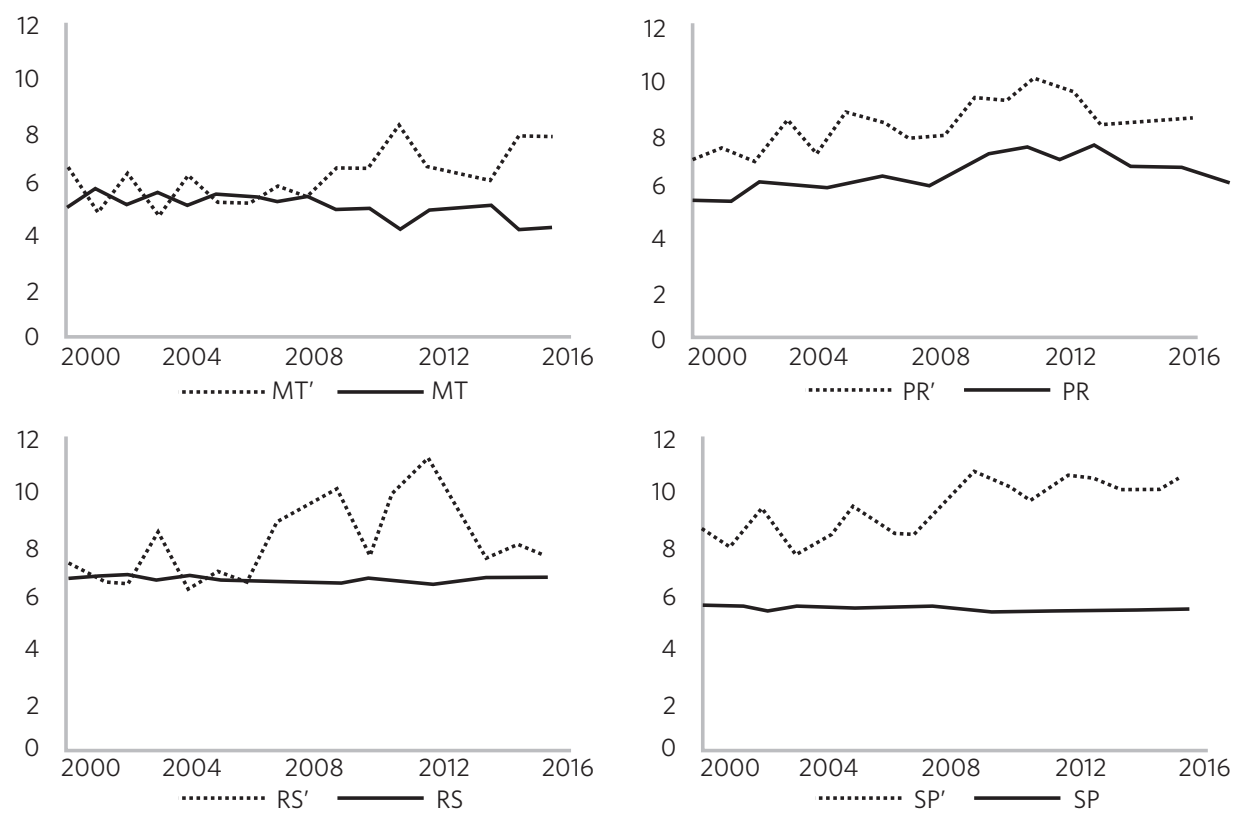

Fonte: Elaboração própria. 
A estimativa de consumo dos agrotóxicos considerados DE para os anos de 2000 e 2016 é apresentada no quadro 1. Os ingredientes ativos dos agrotóxicos que apresentaram maior estimativa de consumo, em ordem decrescente, foram: Glifosato, Trifluralina, Clorotalonil, Diuron e Metalocloro.

Quadro 1. Estimativa do consumo de agrotóxicos disruptores endócrinos pelos estados brasileiros: Mato Grosso (MT), Paraná (PR), Rio Grande do Sul (RS) e São Paulo (SP), nos anos de 2000 e 2016

\begin{tabular}{|c|c|c|c|c|c|c|c|c|}
\hline \multirow{2}{*}{$\begin{array}{l}\text { Ingrediente } \\
\text { ativo } \\
\text { (QuiloLitros/ } \\
\text { hectares) }\end{array}$} & \multicolumn{2}{|l|}{$\mathrm{MT}^{\prime}$} & \multicolumn{2}{|l|}{ MT } & \multicolumn{2}{|l|}{ PR' } & \multicolumn{2}{|l|}{ PR } \\
\hline & 2000 & 2016 & 2000 & 2016 & 2000 & 2016 & 2000 & 2016 \\
\hline $2,4 \mathrm{D}$ & 1.912 & 7.618 & 2.588 & 8.347 & 1.593 & 2.247 & 5.382 & 8.585 \\
\hline Acefato & 1.699 & 5.553 & 2.204 & 6.459 & 953 & 1.498 & 2.620 & 5.148 \\
\hline Atrazina & 1.431 & 10.301 & 2.091 & 10.015 & 3.029 & 3.413 & 11.706 & 12.936 \\
\hline Captana & 362 & 1.575 & 455 & 1.616 & 354 & 468 & 1.064 & 1.421 \\
\hline Carbendazin & 1.449 & 6.821 & 1.799 & 6.742 & 1.611 & 2.079 & 4.898 & 6.172 \\
\hline Carbofurano & 430 & 623 & 940 & 2.420 & 45 & 9 & 1.677 & 3.142 \\
\hline Cipermetrina & 390 & 1.718 & 489 & 1.750 & 389 & 513 & 1.171 & 1.554 \\
\hline Ciproconazol & 695 & 2.700 & 911 & 2.941 & 554 & 783 & 1.735 & 2.741 \\
\hline Clorotalonil & 3.639 & 14.581 & 4.612 & 15.114 & 3.018 & 4.308 & 8.793 & 13.759 \\
\hline Clorpirifós & 1.804 & 7.670 & 2.273 & 7.967 & 1.701 & 2.259 & 5.098 & 6.897 \\
\hline Dimetoato & 58 & 94 & 80 & 230 & 7 & 0 & 22 & 0 \\
\hline Diuron & 3.632 & 13.752 & 5.112 & 16.348 & 2.854 & 3.886 & 10.516 & 16.377 \\
\hline Endosulfan & 2.193 & 6.562 & 3.501 & 9.681 & 1.092 & 1.697 & 5.809 & 11.507 \\
\hline Epoxiconazol & 1.109 & 4.500 & 1.470 & 4.905 & 966 & 1.315 & 3.153 & 4.668 \\
\hline Flutriafol & 1.403 & 5.255 & 1.842 & 5.851 & 1.049 & 1.495 & 3.251 & 5.230 \\
\hline Glifosato & 6.263 & 25.027 & 8.220 & 27.228 & 5.297 & 7.272 & 16.849 & 25.184 \\
\hline Malationa & 1.432 & 4.606 & 1.861 & 5.451 & 783 & 1.223 & 2.156 & 4.203 \\
\hline Metolacloro & 2.717 & 10.832 & 3.647 & 11.975 & 2.294 & 3.153 & 7.657 & 11.650 \\
\hline Metomil & 2.162 & 7.780 & 2.776 & 8.589 & 1.477 & 2.191 & 4.205 & 7.233 \\
\hline Metribuzin & 1.520 & 4.981 & 2.222 & 6.291 & 865 & 1.382 & 3.495 & 7.019 \\
\hline Permetrina & 198 & 710 & 256 & 835 & 142 & 189 & 421 & 591 \\
\hline Simazina & 1.634 & 11.883 & 2.338 & 11.390 & 3.499 & 3.943 & 13.292 & 14.477 \\
\hline Tebuconazol & 2.318 & 9.081 & 3.009 & 9.782 & 1.871 & 2.640 & 5.739 & 8.951 \\
\hline Tebutiurom & 59 & 61 & 245 & 569 & 4 & 4 & 732 & 1.473 \\
\hline Triflurallina & 5.014 & 19.562 & 6.670 & 21.634 & 4.057 & 5.656 & 13.185 & 20.479 \\
\hline
\end{tabular}


Quadro 1. (cont.)

\begin{tabular}{|c|c|c|c|c|c|c|c|c|}
\hline Ingrediente & RS' & & RS & & SP' & & SP & \\
\hline $\begin{array}{l}\text { ativo } \\
\text { (QuiloLitros/ } \\
\text { hectares) }\end{array}$ & 2000 & 2016 & 2000 & 2016 & 2000 & 2016 & 2000 & 2016 \\
\hline $2,4 \mathrm{D}$ & 1.503 & 2.199 & 3.896 & 5.412 & 3.177 & 4.960 & 4.167 & 9.547 \\
\hline Acefato & 1.287 & 2.058 & 2.425 & 4.636 & 427 & 338 & 315 & 709 \\
\hline Atrazina & 889 & 464 & 6.636 & 3.172 & 8.372 & 13.262 & 12.314 & 25.789 \\
\hline Captana & 267 & 366 & 819 & 959 & 185 & 126 & 276 & 316 \\
\hline Carbendazin & 1.085 & 1.414 & 3.687 & 3.888 & 858 & 573 & 1.345 & 1.474 \\
\hline Carbofurano & 16 & 10 & 142 & 76 & 5.110 & 9.364 & 7.001 & 17.484 \\
\hline Cipermetrina & 290 & 394 & 900 & 1.040 & 204 & 138 & 306 & 349 \\
\hline Ciproconazol & 533 & 787 & 1.342 & 1.919 & 672 & 929 & 869 & 1.832 \\
\hline Clorotalonil & 2.946 & 4.365 & 7.321 & 10.591 & 1.494 & 1.084 & 1.741 & 2.555 \\
\hline Clorpirifós & 1.315 & 1.817 & 3.945 & 4.721 & 885 & 603 & 1.313 & 1.509 \\
\hline Dimetoato & 0 & 0 & 0 & 0 & 4 & 0 & 31 & 3 \\
\hline Diuron & 2.488 & 3.562 & 6.862 & 8.963 & 8.333 & 13.684 & 11.293 & 26.104 \\
\hline Endosulfan & 1.474 & 2.327 & 2.981 & 5.342 & 9.757 & 17.450 & 12.853 & 32.645 \\
\hline Epoxiconazol & 818 & 1.162 & 2.296 & 2.942 & 1.447 & 2.099 & 1.965 & 4.116 \\
\hline Flutriafol & 1.048 & 1.565 & 2.546 & 3.771 & 1.205 & 1.640 & 1.548 & 3.239 \\
\hline Glifosato & 4.637 & 6.662 & 12.617 & 16.672 & 6.659 & 9.196 & 8.978 & 18.220 \\
\hline Malationa & 1.051 & 1.680 & 1.980 & 3.784 & 352 & 276 & 281 & 581 \\
\hline Metolacloro & 2.013 & 2.889 & 5.501 & 7.242 & 4.076 & 6.180 & 5.479 & 11.989 \\
\hline Metomil & 1.668 & 2.567 & 3.647 & 5.999 & 703 & 526 & 717 & 1.186 \\
\hline Metribuzin & 1.194 & 1.897 & 2.331 & 4.313 & 4.092 & 7.138 & 5.207 & 13.384 \\
\hline Permetrina & 120 & 173 & 325 & 432 & 73 & 49 & 115 & 121 \\
\hline Simazina & 1.025 & 535 & 7.647 & 3.654 & 8.912 & 13.922 & 13.204 & 27.183 \\
\hline Tebuconazol & 1.784 & 2.628 & 4.519 & 6.416 & 1.832 & 2.326 & 2.359 & 4.679 \\
\hline Tebutiurom & 7 & 5 & 66 & 36 & 2.384 & 4.390 & 3.206 & 8.189 \\
\hline Triflurallina & 3.745 & 5.462 & 9.779 & 13.474 & 6.271 & 9.245 & 8.317 & 18.015 \\
\hline
\end{tabular}

Fonte: Elaboração própria.

(') microrregiões analisadas no estado.

\section{Discussões}

Em relação ao consumo de agrotóxicos no Brasil, entre 2007 e 2013, a relação de comercialização por área plantada aumentou em 1,59 vez, passando de 10,32 quilos por hectare $(\mathrm{kg} /$ ha) para $16,44 \mathrm{~kg} / \mathrm{ha}$. Nesse período, o quantitativo de agrotóxicos comercializados no País passou de, aproximadamente, 643 milhões para 1,2 bilhão de quilos, e a área plantada total aumentou de 62,33 milhões para 74,52 milhões de hectares. Isso representa um aumento de 90,49\% na comercialização de agrotóxicos e uma ampliação de 19,5\% de área plantada ${ }^{14,17}$.

Para os estados selecionados neste estudo, observa-se que, no ano de 2000, foram comercializados 18.077,62 (MT); 41.795,20(SP); 27.606,20 (PR) e 18.589,68 (RS) toneladas de 
agrotóxicos. No mesmo período, foram destinados ao plantio de commodities 3.862.021 (MT); 4.169 .930 (SP); 5.905 .481 (PR) e 35.425.794 (RS) hectares. Já no ano de 2016, foram comercializados 104.901,05 (MT); 76.444,55 (SP); 72.212,38 (PR) e 63.352,27 (RS) toneladas de agrotóxicos e destinados ao plantio de commodities 13.934.636 (MT); 7.310.830 (SP); 8.654.981 (PR) e 43.077.462 (RS) hectares. De 2000 para 2016, houve um crescimento na comercialização de agrotóxicos de 480,3\% (MT), 82,9\% (SP), 161,6\% (PR) e 240,8\% (RS). Ao mesmo tempo, o aumento de áreas destinadas ao plantio foi de $139,6 \%$ (MT), 50,3\% (SP), 32,4\% (PR) e 27,3\% (RS). Se comparados, o aumento da comercialização de agrotóxicos foi muito superior ao aumento das áreas destinadas ao plantio para todos os estados. Esses números são indicativos do aumento da exposição da população ao longo do tempo.

Os dados apresentados corroboram a influência da presença dos agrotóxicos nos desfechos analisados. No entanto, é importante ressaltar que poucos estudos analisam a incidência de $\mathrm{MC}$ e a exposição à agrotóxicos específicos. Isso porque há enorme dificuldade metodológica na quantificação dessa exposição, uma vez a população está sujeita à múltiplos produtos químicos por meio de diferentes vias de contaminação e absorção.

A existência de biomarcadores confiáveis para análise também é outra dificuldade metodológica enfrentada. Além disso, na maioria das vezes, é necessário que haja mais de uma metodologia para que se consiga analisar diferentes metabólitos e princípios ativos. A distribuição dos produtos químicos no corpo também não é homogênea, uma vez que cada substância tem afinidade com determinadas células, o que também acarreta problemas metodológicos, pois nem sempre uma mesma amostra será a mais indicada para todos os tipos de substâncias que se pretende analisar.

Um estudo coorte avaliou a exposição in utero a pesticidas medindo biomarcadores do soro materno e medular em uma coorte de mulheres grávidas em New Jersey e os desfechos de nascimento de seus neonatos. Foram encontradas concentrações elevadas de metolacloro no sangue do cordão umbilical que foram relacionadas ao baixo peso ao nascer. Foi sugerido que a exposição intraútero a agrotóxicos podem alterar os desfechos perinatais ${ }^{19}$.

Com efeito, utilizaram-se dados sobre a área destinada à produção de grãos, e foi realizada a estimativa de consumo baseada no quantitativo informado nas bulas dos agrotóxicos. Apesar de não ser uma medida de exposição individual, o que se apresenta como um fator de limitação deste estudo, essa mensuração é um meio para a realização de tais pesquisas, uma vez que o País não dispõe de banco de dados sistematizados que forneçam estas informações. Outros estudos brasileiros também utilizaram metodologias semelhantes ${ }^{\mathbf{2 0 - 2 4}}$.

Froes Asmus et al. ${ }^{25}$ observaram a correlação positiva entre as vendas de agrotóxicos e determinadas MC. Esse estudo investigou a associação entre a exposição a agrotóxicos no Brasil (2005-2013) e as taxas de MC do sistema nervoso central e cardiovascular em 2014. A variável de exposição foi estabelecida a partir dos dados sobre produção e vendas de agrotóxicos (Kg) por área de cultivo (ha) para os anos de 2012 e 2013. Os estados brasileiros foram divididos em três categorias: uso de agrotóxicos alto, médio e baixo, e foram estimados os índices de taxas para cada grupo de estados. Em 2013 e 2014, o grupo de alto uso apresentou um aumento de $100 \%$ e $75 \%$ e o grupo mediano apresentou um aumento de $65 \%$ e $23 \%$, respectivamente, no risco dessas anomalias congênitas quando comparados ao grupo de baixo uso. Esses resultados sugerem que a quantidade de agrotóxicos comercializados é um fator importante na determinação da exposição e ocorrência de efeitos adversos, além de estar associado a um maior risco de prevalência dessas MC no Brasil.

$\mathrm{Na}$ análise ecológica desenvolvida por Siqueira et al. ${ }^{20}$, foi observada a exposição aos agrotóxicos, incluindo os 26 estados brasileiros. Os autores observaram que a exposição a agrotóxicos era fraca, mas significativamente 
correlacionada com a taxa de mortalidade infantil por $\mathrm{MC}(\mathrm{r}=0,49 ; p=0,039)$ e médio, porém não significativamente correlacionado com MC ao nascimento $(\mathrm{r}=0,65 ; p=0,664)$.

Um outro estudo brasileiro, do tipo caso-controle, avaliou a associação entre a exposição dos genitores aos agrotóxicos e o nascimento de crianças com MC no Vale do São Francisco. A análise das variáveis relacionadas à exposição aos agrotóxicos mostrou um aumento do risco de ocorrência de MC quando foram considerados: ambos os pais vivendo e trabalhando perto de lavouras; moradia próxima a lavouras; pai trabalhando na lavoura; pai aplicando produtos na lavoura e exposição aos agrotóxicos de pelo menos um dos progenitores. No entanto, não houve diferença estatística significativa entre os casos e os controles ${ }^{26}$.

No que se refere ao glifosato, o estudo transversal de Garry et al. ${ }^{27}$ demonstrou maior frequência de $\mathrm{MC}$ em recém-nascidos do Vale do Rio Vermelho, Minnesota, uma região de grande prática agrícola dos EUA. O uso do herbicida glifosato foi relacionado especialmente com transtornos neurocomportamentais (OR=3,6, IC95\%=1,3-9,6).

No estudo de coorte de Gaspari et al. ${ }^{28}$, buscou-se estabelecer as incidências de malformações genitais masculinas neonatais, investigar as etiologias endócrinas e genéticas dessas malformações e avaliar suas associações com uma possível exposição pré-natal a DE, em hospitais regionais de Campina Grande (Paraíba, Brasil). Foram avaliados 2.710 recém-nascidos do sexo masculino em relação à criptorquidia, hipospádia e micropênis. Além de investigações endócrinas e genéticas, todos os pais foram entrevistados sobre sua exposição ambiental/ocupacional a DE. Foram observados 56 casos de malformação genital (2,07\%), incluindo 23 criptorquidismo (0,85\%), 15 hipospádias (0,55\%) e 18 micropênis $(0,66 \%)$, sendo que nenhum caso apresentou mutação no receptor de andrógeno ou no gene da $5 \alpha$-redutase. Mais de $92 \%$ desses recém-nascidos apresentaram contaminação fetal por DE, já que suas mães relataram uso doméstico diário de pesticidas (DicloroDifenil-Tricloroetano - DDT) e outros DE. Além disso, a maioria desses recém-nascidos masculinos apresentou contaminação adicional por DE, pois $80,36 \%$ das mães e $58,63 \%$ dos pais relataram trabalho remunerado ou não remunerado que envolvia o uso de pesticidas e outros DE antes/durante a gravidez para as mães, e na época da fertilização para os pais. A alta taxa de micropênis na população estudada foi associada a um percentual elevado de exposição ocupacional/ambiental dos pais.

Já o estudo de Cremonese et al. ${ }^{21}$ associou o consumo de agrotóxicos per capita nos anos de 1985 e 1996 com as taxas de mortalidade infantil por MC do Sistema Nervoso Central e Sistema Circulatório nos períodos 1986-1990 e 1997-2001, respectivamente, nas regiões Sul e Sudeste. As microrregiões do estudo foram classificadas em rurais e urbanas. Os autores referiram uma tendência significativa de aumento na taxa de mortalidade infantil para os dois tipos de malformações, nas microrregiões rurais, mas não nas regiões urbanas do Brasil.

No estudo desenvolvido por Oliveira et al. ${ }^{23}$, foram selecionados oito municípios com maior quantidade de agrotóxicos comercializados por área de cultivo na região de estudo (Mato Grosso), observando que a exposição materna ao agrotóxico foi significativamente associada à maior incidência de MC. Esses estudos brasileiros estão em acordo com os achados desta pesquisa.

No estudo desenvolvido na análise da associação entre MC e a utilização de agrotóxicos em monoculturas no PR, encontrou-se que as taxas referentes ao estado foram maiores que as encontradas na Unidade Regional (UR) de maior exposição. É importante ressaltar que as análises das UR se referem a um total de 55 municípios, sendo esta uma parcela $(13,8 \%)$ do total (399) de municípios do estado. Também é relevante dizer que, se todo o estado fosse analisado por intermédio das UR apresentadas pela Adapar, haveria mais 193 municípios classificados em 'alto consumo de agrotóxicos’ e 151 municípios classificados em ‘baixo 
consumo de agrotóxicos'. Assim, os dados referentes ao estado demonstram que, ao longo do tempo, o agronegócio tem avançado e que, apesar de haver regiões mais ou menos agrárias presentes no estado, a contaminação da população aumenta, demonstrando que as fronteiras agrícolas e os desdobramentos referentes a ela estão cada vez mais próximos de centros urbanos, seja por meio de uma aproximação literalmente física ou por meio dos contaminantes existentes na água, no ar ou nos alimentos ingeridos por essa população ${ }^{29}$.

O estudo longitudinal realizado no México por Castillo-Cadena; Mejia-Sanchez; LópezArriaga $^{\mathbf{3 0}}$ buscou determinar a frequência e etiologia das MC em recém-nascidos em uma comunidade floricultural (Hospital Geral Tenancingo) e compará-las a uma comunidade urbana (Hospital de Ginecologia e Obstetrícia da Mãe e da Criança - Imiem). Segundo a etiologia, em Tenancingo, 69\% das MC eram multifatoriais; $28 \%$, monogenéticos; e $2 \%$, cromossômicos. No Imiem, $47 \%$ das MC eram multifatoriais, $18,3 \%$ eram monogenéticos e $2,8 \%$ eram cromossômicos. Houve uma diferença significativa entre a frequência global de malformações e etiologia multifatorial entre as instituições. Os resultados mostraram que as MC ocorreram com maior frequência na zona de floricultura e que, pelo fato de a porcentagem de etiologia multifatorial ser maior, é provável que exista uma associação com a exposição a agrotóxicos.

García et al. ${ }^{31}$ realizaram um estudo de caso-controle sobre a associação de transtornos reprodutivos e anomalias congênitas com exposição ambiental a agrotóxicos com atividades DE. Foi determinada a prevalência e o risco de desenvolver transtornos gestacionais e malformações geniturinárias masculinas congênitas em áreas com alta exposição e baixa exposição a agrotóxicos DE. A população de estudo incluiu 45.050 casos e 950.620 controles emparelhados por idade e distrito de saúde. Os dados foram coletados de registros computadorizados do hospital entre 1998 e 2005. As taxas de prevalência e risco de aborto espontâneo, baixo peso ao nascer, hipospadias, criptorquidia e micropênis foram significativamente maiores em áreas com maior uso de agrotóxicos em relação aquelas com menor uso.

No estudo de Toichuev et al. ${ }^{32}$, foram examinadas 241 placentas de regiões produtoras de algodão, 121 placentas de área urbana (cidade de Osh) e 146 placentas de regiões montanhosas não poluídas do Quirguistão, investigando-se se havia, nessas amostras, a presença de determinados agrotóxicos organoclorados (OCP). Além disso, foram verificadas manifestações de doenças nas mães, durante a gravidez e parto, e em seus recém-nascidos durante os primeiros 6 dias de vida. OCP foram detectados em $47,2 \%$ das amostras, com incidência aumentada nas duas regiões poluídas (65\%), particularmente em placentas de mulheres que vivem perto de antigos armazéns de agrotóxicos e pistas de pouso agrícolas (99\%), mas apenas em $2,7 \%$ das mulheres que viviam na região não poluída. Houve aumento significativo do risco relativo a problemas de saúde em mães e recém-nascidos, diretamente proporcionais à concentração de $\mathrm{OCP}$, sendo estes: baixo peso ao nascer, $\mathrm{MC}$, infecções e natimortos, no parto prematuro de mães expostas ao OCP, (pré-) eclâmpsia/gestose e frequência de hospitalizações após o parto (infecções). $\mathrm{O}$ estudo concluiu que as mulheres que vivem perto de antigos armazéns de agrotóxicos ou de pistas de pouso agrícolas devem ser consideradas em risco.

No contexto de contaminação por agrotóxicos, a população rural tende a ser a mais atingida. Um estudo divulgado há pouco tempo pelo IBGE propõe nova metodologia para a reclassificação dos municípios entre rural e urbano. Pelos critérios atuais, o espaço urbano é determinado por lei municipal, sendo o rural definido por exclusão à área urbana. Ainda segundo o documento, os limites oficiais entre zona urbana e zona rural são, em grande parte, instrumentos definidos segundo objetivos fiscais que enquadram os domicílios sem considerar necessariamente as características territoriais e sociais do município e de seu entorno ${ }^{33}$. 
Assim, ainda que boa parte dos brasileiros viva nas áreas predominantemente urbanas, o número de cidades com essas características seria de apenas $26 \%$ das 5.565 existentes. Pelo levantamento realizado, o País teria mais municípios predominantemente rurais, que representariam $60,4 \%$ das cidades brasileiras, tendo estes espaços características relacionadas com a matriz econômica brasileira, que é voltada para a produção de commodities ${ }^{33}$.

Em relação às áreas urbanas brasileiras, há uma tendência atual de aumento do uso de agrotóxicos, devido aos esforços de combater os surtos de doenças transmitidas por vetores, como é o caso da infecção pelo vírus Zika. Essa ação pode, potencialmente, aumentar a exposição a pesticidas para toda a população, incluindo mulheres grávidas.

Para a população geral, a dieta é considerada como a principal via de exposição aos agrotóxicos, por meio dos resíduos deixados por essas substâncias nos alimentos. O Programa de Avaliação de Resíduos de Pesticidas em Alimentos (Para) foi desenvolvido pela Agência de Vigilância Sanitária (Anvisa) do Brasil em 2001. Esse programa mede as concentrações e os tipos de resíduos de ingredientes ativos nas lavouras. Em 2012, foram analisadas 1.397 amostras de culturas. Em 25\% das análises, foram detectados resíduos de ingredientes ativos acima dos limites máximos (MLR Limite Máximo de Resíduo) ou ingredientes ativos não legalizados ${ }^{34}$.

O Departamento de Vigilância Sanitária do Ministério da Saúde do Brasil vem realizando o Programa Nacional de monitoramento de resíduos de agrotóxicos em água potável, em todos os municípios do País, desde a última década. No ano de 2013, foram coletadas amostras de água potável em 1.598 municípios. A análise identificou, pelo menos, uma amostra acima dos limites máximos de resíduos de agrotóxicos na água potável em 337 (21\%) municípios ${ }^{35}$.

Agrotóxicos como a atrazina, o alacloro e o clorpirifós são classificados como DE, enquanto outros, como diuron e bifentrina, são classificados como substâncias tóxicas à reprodução.
Além de possuírem classificações distintas, os agrotóxicos considerados teratogênicos também possuem diversos mecanismos de ação. Eles podem atravessar a placenta e serem absorvidos sistemicamente, podem agir por meio da desregulação endócrina, da indução ao dano genético, causando defeitos nas células neuronais e o estresse oxidativo, sendo estes os mecanismos propostos como principais para a toxicidade desses produtos perante o desenvolvimento ${ }^{36}$. Levando-se em conta esses fatores, não se sabe qual a possibilidade de potencialização ou anulação dos efeitos quando existem tantos princípios ativos com mecanismos de ação e toxicologia diversos interagindo no corpo e no meio ambiente.

Outro fator a ser mencionado é a fonte de dados utilizada. Embora tenha havido melhora constante do alcance e capacidade de registro do Sinasc, a subnotificação de dados pode constituir uma limitação deste estudo. Estudos realizados no Brasil analisando a qualidade dos dados obtidos nas declarações de nascimento, baseados no Sinasc, revelaram uma subnotificação de $\mathrm{MC}$ ao nascimento em várias regiões do País ${ }^{37}$.

Outros fatores importantes de serem mencionados, que não puderam ser mensurados neste estudo, são os óbitos fetais e os abortos espontâneos. Regidor et al. ${ }^{\mathbf{3 8}}$ demonstraram que famílias de agricultores tiveram maior risco de apresentarem gestações com desfecho em morte fetal em áreas onde os agrotóxicos são mais utilizados quando comparadas a outras regiões da Espanha, sendo o risco ainda maior quando o período da concepção coincide com o máximo uso dos agrotóxicos. Um estudo italiano verificou a presença de agrotóxicos DE em 11 em um total de 24 natimortos, incluindo agrotóxicos organoclorados e organofosforados como clordano, heptacloro, clorfenvinfós, clorpirifós, e ainda aqueles cujo uso está banido como DDT e seu metabólito $\mathrm{DDE}^{39}$. Pode-se inferir que muitos casos de MC resultaram em óbitos fetais e abortos espontâneos, o que tornaria os números relacionados com o desfecho estudado ainda maiores. 
Apesar dos obstáculos metodológicos que dificultam a elaboração de estudos sobre o assunto, é importante que pesquisas sejam realizadas para alertar sobre problemas de saúde causados à população e propor novas soluções perante a utilização maciça desses produtos químicos. Outro obstáculo é o controle efetivo da comercialização desses itens, que é muito pequena no cenário brasileiro. Os dados referentes ao uso de produtos não são sistematizados em bancos de dados informatizados para a grande maioria dos estados. Isso dificulta medir o impacto da exposição sofrida pela população. Além disso, há grandes investimentos fornecidos às indústrias de agrotóxicos no comércio brasileiro. Vários subsídios governamentais foram concedidos direta ou indiretamente a essas empresas, quer pela obtenção de crédito rural previsto àqueles que adotam esse modelo de agricultura, quer pela isenção do imposto sobre o comércio de agrotóxicos, o que, consequentemente, aumenta o consumo dessas substâncias.

Outro agravante nesse contexto é a permissão que garante às empresas o direito de comercializar no Brasil produtos proibidos no estrangeiro, o que demonstra uma fraca política de monitoramento ambiental no consumo de agrotóxicos por parte do governo brasileiro. Por meio da ação do lobby exercido por essas empresas em parlamentares e gestores, há pressões políticas e econômicas intensas sobre órgãos reguladores brasileiros responsáveis pelas reavaliações desses produtos, gerando interferência nas decisões nacionais sobre a matéria. Atualmente, o Projeto de Lei ${ }^{\circ}$ 6.299/2002 está sendo discutido no parlamento brasileiro, o que tornaria ainda mais fácil a comercialização de substâncias que já foram proscritas em outros países. Diversas entidades científicas e a sociedade civil enviaram notas de repúdio a tal projeto ${ }^{40}$. A Organização das Nações Unidas (ONU) enviou, especificamente, uma carta ao governo brasileiro indicando que esse projeto significa um enfraquecimento dos critérios de aprovação para a comercialização de pesticidas, constituindo uma ameaça aos direitos humanos ${ }^{41}$.

\section{Conclusões}

Os dados apresentados sustentam a ideia de que a exposição ambiental sofrida pela população das microrregiões e estados estudados tem aumentado ao longo do tempo e tem influenciado na incidência de MC. É necessário que haja o aprimoramento do controle do uso de agrotóxicos, associado a uma avaliação rigorosa desses contaminantes no ambiente, incluindo alimentos, água potável, ar e solo. Considerando que, no Brasil, o comércio de agrotóxicos tem apresentado crescimento exponencial nos últimos 10 anos, o estabelecimento de ações de vigilância referente a esses produtos torna-se ainda mais essencial.

O impacto potencial dos agrotóxicos na saúde humana tem sido um tópico relevante de debate na sociedade científica internacional. Sob essas circunstâncias, este estudo visa alertar para os problemas relacionados com o uso de agrotóxicos no País, e pretende contribuir para o melhoramento de políticas públicas que visem à diminuição e ao controle do uso dessas substâncias.

\section{Colaboradores}

Dutra LS (0000-0003-3350-1365)* contribuiu para a concepção, o planejamento, a análise e a interpretação dos dados; revisão crítica do conteúdo; e aprovação da versão final do manuscrito. Ferreira AP (0000-0002-7122-5042)* contribuiu para a revisão crítica do conteúdo e a aprovação da versão final. 


\section{Referências}

1. Moore KL, Persaud TV. Defeitos congênitos humanos. In: KL Moore, TV Persaud, editores. Embriologia clínica. 9. ed. Rio de Janeiro: Guanabara Koogan; 2016. p. 161-93.

2. Stillerman KP, Mattison DR, Giudice LC, et al. Environmental exposures and adverse pregnancy outcomes: a review of the science. Reprod Sci. 2008; 15(7):631-650.

3. Sadler TW. Langman embriologia médica. 12. ed. Rio de Janeiro: Guanabara Koogan; 2013.

4. Lemaire G, Mnif W, Pascussi J-M, et al. Identification of new human pregnane $\mathrm{X}$ receptor ligands among pesticides using a stable reporter cell system. Toxicol Sci. 2006; 91(2):501-509.

5. Tabb MM, Blumberg B. New modes of action for endocrine-disrupting chemicals. Mol Endocrinol. 2006; 20(3):475-482.

6. Leghait J, Gayrard V, Picard-Hagen N, et al. Fipronil-induced disruption of thyroid function in rats is mediated by increased total and free thyroxine clearances concomitantly to increased activity of hepatic enzymes. Toxicology. 2009; 255(1-2):38-44.

7. World Health Organization. O Pesticides [internet]. Genebra, Suiça: WHO; 2019. [acesso em 2018 jun 22]. Disponível em: http://www.who.int/topics/pesticides/en/.

8. Van den Berg H, Zaim M, Yadav RS, et al. Global trends in the use of insecticides to control vector-borne diseases. Environ Health Perspect. 2012; 120(4):577582 .

9. Grube A, Donaldson D, Kiely T, et al. Pesticides industry sales and usage 2006 and 2007 market estimates. Washington, D.C: United States Environmental Protection Agency; 2011 [acesso em 2018 jun 22]. Disponível em: https://www.epa.gov/sites/production/files/2015-10/documents/market_estimates2007.pdf.
10. Sparling DW. Current Use Pesticides. In: Sparling DW, organizador. Ecotoxicology Essentials [internet]. San Diego: Academic Press; 2016. p. 109-52. [acesso em 2019 jul 3]. Disponível em: http://www.sciencedirect. com/science/article/pii/B9780128019474000056.

11. Rosa IF, Pessoa VM, Rigotto RM. Introdução: agrotóxicos, saúde humana e os caminhos do estudo epidemiológico. In: Rigotto RM, organizador. Agrotóxicos, Trabalho e Saúde - vulnerabilidade e resistência no contexto da modernização agrícola no Baixo Jaguaribe/CE. São Paulo: Edições UFC; 2011. p. 217-56.

12. Rede Interagencial de Informações para Saúde. Demografia e saúde: contribuição para análise de situação e tendências. Brasília, DF: Organização Pan-Americana da Saúde; 2009. 144 p.

13. Nasrala Neto E, Lacaz FAC, Pignati WA, et al. Vigilância em saúde e agronegócio: os impactos dos agrotóxicos na saúde e no ambiente. Perigo à vista! Ciênc. Saúde Colet. 2014; 19(12):4709-4718.

14. Instituto Brasileiro de Geografia e Estatística. Sistema IBGE de Recuperação Automática: SIDRA [internet]. Rio de Janeiro: IBGE; 2019 [acesso em 2018 jun 22]. Disponível em: https://sidra.ibge.gov.br/pesqui$\mathrm{sa} /$ pam/tabelas.

15. Mnif W, Hassine AIH, Bouaziz A, et al. Effect of Endocrine Disruptor Pesticides: A Review. Int. j. environ. res. public health. 2011; 8(6):2265-2303.

16. Brasil. Ministério da Agricultura, Pecuária e Abastecimento. Agrofit: Sistema de Agrotóxicos Fitosanitários [internet]. Brasília, DF: MAPA; 2019 [acesso em 2018 ago 20]. Disponível em: http://agrofit.agricultura.gov.br/agrofit_cons/principal_agrofit_cons.

17. Instituto Brasileiro do Meio Ambiente e dos Recursos Naturais Renováveis. Relatórios de comercialização de agrotóxicos [internet]. Brasília, DF: Ibama; 2016 [acesso em 2018 jul 16]. Disponível em: https://www. ibama.gov.br/agrotoxicos/relatorios-de-comercializacao-de-agrotoxicos. 
18. Kim HJ, Fay MP, Feuer EJ, et al. Permutation tests for joinpoint regression with applications to cancer rates. Stat Med. 2000; 19(3):335-351.

19. Barr DB, Ananth CV, Yan X, et al. Pesticide concentrations in maternal and umbilical cord sera and their relation to birth outcomes in a population of pregnant women and newborns in New Jersey. Sci Total Environ [internet]. 2010 [acesso em 2018 ago 5]; 408(4):790-795. Disponível em: http://dx.doi. org/10.1016/j.scitotenv.2009.10.007.

20. Siqueira MT, Braga C, Cabral-Filho JE, et al. Correlation between pesticide use in agriculture and adverse birth outcomes in Brazil: an ecological study. Bull. environ. contam. toxicol. 2010; 84(6):647-651.

21. Cremonese C, Freire C, De Camargo AM, et al. Pesticide consumption, central nervous system and cardiovascular congenital malformations in the South and Southeast region of Brazil. Int. j. occup. med. environ. health. 2014; 27(3):474-486.

22. McKinnish T, Rees DI, Langlois PH. Seasonality in birth defects, agricultural production and urban location. Econ. hum. biol. 2014; 15:120-128.

23. Oliveira NP, Moi GP, Atanaka-Santos M, et al. Congenital defects in the cities with high use of pesticides in the state of Mato Grosso, Brazil. Ciênc. Saúde Colet. 2014; 19(10):4123-4130.

24. Markel TA, Proctor C, Ying J, et al. Environmental pesticides increase the risk of developing hypertrophic pyloric stenosis. J. pediatr. surg. 2015; 50(8):12831288.

25. Froes Asmus CIR, Camara VM, Raggio R, et al. Positive correlation between pesticide sales and central nervous system and cardiovascular congenital abnormalities in Brazil. Int. j. environ. health res. 2017; 27(5):420-426.

26. Silva SRG, Martins JL, Siexas S, et al. Defeitos congênitos e exposição a agrotóxicos no Vale do São Francisco. Rev. bras. ginecol. obstet. 2011; 33(1):20-26.
27. Garry VF, Harkins ME, Erickson LL, et al. Birth defects, season of conception, and sex of children born to pesticide applicators living in the Red River Valley of Minnesota, USA. Environ. health perspect. 2002; $110(3): 441-449$.

28. Gaspari L, Sampaio DR, Paris F, et al. High prevalence of micropenis in 2710 male newborns from an intensive-use pesticide area of Northeastern Brazil. Int. j. androl. 2012; 35(3):253-264.

29. Dutra LS, Ferreira AP. Associação entre malformações congênitas e a utilização de agrotóxicos em monoculturas no Paraná, Brasil. Saúde debate. 2017; 41(esp2):241-253.

30. Castillo-Cadena J, Mejia-Sanchez F, López-Arriaga JA. Congenital malformations according to etiology in newborns from the floricultural zone of Mexico state. Environ Sci Pollut Res Int. 2017; 24(8):76627662 .

31. García J, Ventura MI, Requena M, et al. Association of reproductive disorders and male congenital anomalies with environmental exposure to endocrine active pesticides. Reprod. toxicol. 2017; 71:95-100.

32. Toichuev RM, Zhilova LV, Paizildaev TR, et al. Organochlorine pesticides in placenta in Kyrgyzstan and the effect on pregnancy, childbirth, and newborn health. Environ Sci Pollut Res Int. 2018; 25(32):3188531894.

33. Instituto Brasileiro de Geografia e Estatística. Classificação e caracterização dos espaços rurais e urbanos do Brasil: uma primeira aproximação. Rio de Janeiro: IBGE; 2017. 78 p.

34. Agência Nacional de Vigilância Sanitária. Programa de Análise de Resíduos de Agrotóxicos em Alimentos [internet]. Brasília, DF: ANVISA, 2019 [acesso em 2019 jul 3]. Disponível em: http://portal.anvisa.gov. br/programa-de-analise-de-registro-de-agrotoxicos-para. 
35. Brasil. Ministério da Saúde, Secretaria de Vigilância em Saúde. Relatório Nacional Vigilância em Saúde de Populações Expostas a Agrotóxicos. Brasília, DF: MS; 2016. 141 p.

36. Van Gelder MMHJ, Van Rooij IALM, Miller RK, et al. Teratogenic mechanisms of medical drugs. Hum. reprod. updat. 2010; 16(4):378-394.

37. Luquetti DV, Koifman RJ. Quality of reporting on birth defects in birth certificates: case study from a Brazilian reference hospital. Cad. Saúde Pública. 2009; 25:1721-1731.

38. Regidor E, Ronda E, García AM, et al. Paternal exposure to agricultural pesticides and cause specific fetal death. Occup. environ. med. 2004; 61(4):334-339.

39. Roncati L, Piscioli F, Pusiol T. The endocrine disruptors among the environmental risk factors for stillbirth. Sci. total environ. 2016; 563-564:1086-1087.
40. Associação Brasileira de Pós-Graduação em Saúde Coletiva. SBPC posiciona-se contra "Lei do Veneno”, em tramitação na Câmara dos Deputados [internet]. Rio de Janeiro: Abrasco, 2018 [acesso em 2018 fev 12]. Disponível em: https://www.abrasco.org.br/ site/outras-noticias/saude-da-populacao/sbpc-posiciona-se-contra-lei-do-veneno-em-tramitacao-na-camara-dos-deputados/34318/.

41. Escritório do Alto Comissário das Nações Unidas para os Direitos Humanos. Comments on legislation and policy [internet]. Geneva: OHCHR. [acesso em 2018 abr 22]. Disponível em: https://www.ohchr.org/EN/ Issues/Environment/ToxicWastes/Pages/Comments. aspx.

Recebido em 30/10/2018 Aprovado em 28/04/2019 Conflito de interesses: inexistente

Suporte financeiro: não houve 